\title{
Medically Unexplained Symptoms (MUS): What Do Current Trainee Psychologists, Neurologists and Psychiatrists Believe?
}

\author{
Steven Kemp, Catherine Spilling, Christine Hughes, Karel de Pauw \\ St James's University Hospital, Leeds, UK \\ Email: steven.kemp@leedsth.nhs.uk
}

Received August 1, 2012; revised September 22, 2012; accepted October 5, 2012

\begin{abstract}
Objectives: Medically unexplained symptoms (MUS) are common in all medical settings. These conditions remain controversial, aetiology remains poorly understood and treatments have been slow to develop. This study aimed to examine the beliefs held by psychologists and other professionals about MUS, which may impact upon clinical practice. Design: 375 clinical psychology trainees from 23 UK training courses, 12 neurologists and 19 psychiatrists in training completed a weblink survey designed to elicit a range of beliefs about MUS cause and treatment. Results: All three groups viewed MUS as a common clinical problem. Use of terminology differed between groups. All three groups held a view that sexual abuse was a medium to high risk factor for developing MUS. Only a minority of psychologists and psychiatrists doubted that the human mind is capable of massive repression for past distressing events; and few psychologists, and no psychiatrists, doubted the traditional psychodynamic causal model of MUS. Neurologists were generally more skeptical. Only a minority of all three groups disagreed that hypnosis was a helpful way to uncover memories that people can not access. Around one third of each group believed that traumatic memories recovered in therapy were reliable. Dualistic thinking was prevalent among all three groups, but more so among psychiatrists. Conclusions: The data show that many professsionals hold beliefs about MUS for which, empirical support is lacking. These beliefs may impact on clinical practice. Whether such beliefs are deemed to be correct or incorrect, they should be acknowledged.
\end{abstract}

Keywords: Medically Unexplained Symptoms; Somatisation; Dissociation; Clinical Training

\section{Introduction}

Patients who present with symptoms that are unexplained by organic disease are common in all medical settings and use considerable health service resources [1]. Carson and colleagues [2] found that one third of new referrals to a general neurology clinic had symptoms that were poorly explained by an identifiable medical condition. Parry Murray, Hart and Bass [3] studied a sample of neurology inpatients and found that nine percent were likely to have a non-organic disorder, with many patients referred via $A \& E$ and being no less costly than those with organic disease. Psychogenic non-epileptic seizures (PNES) is perhaps the best example of a medically unexplained presentation as a test exists (i.e., video EEG) to help differentiate it from epilepsy (i.e., an organic disorder). Other medical causes for seizures also need to be excluded before seizures are regarded as psychogenic. Video EEG is the gold standard for diagnosing epileptic seizures and PNES [4,5]; although a negative ictal EEG does not unequivocally exclude epilepsy [6]. Consequently PNES is well studied and there is a consensus that among patients with drug-resistant seizures between $20 \%$ and $45 \%$ of patients have PNES and not epilepsy $[7,8]$. UK neurologists have described patients with functional neurological symptoms (FNS) as the most difficult to help and FNS came bottom of a recent survey of US neurologists "most likeable conditions" [9].

Wessely and White [10] concluded that functional somatic symptoms and syndromes are a major health issue and that each medical sub-speciality seems to have at least one medically unexplained syndrome. In a recent paper; Kanaan, Armstrong \& Wessely [11] report that although Neurologists' accept psychological models for conversion disorder, they do not see conversion as clearly different from feigning.

Medically unexplained symptoms (MUS) has become the currently accepted scientific term for what was previously, and sometimes still is, referred to as hysteria, functional, non-organic or psychosomatic. Or in formal mental health nomenclature: Somatoform Disorder, Conversion Disorder, Dissociative Disorder or Somatisation. While all these terms may essentially refer to the same 
clinical phenomenon, terms like Dissociative Disorder (attributable to Janet), which is used by the DSM IV, or Conversion Disorder (attributable to Freud), used by the ICD 10, have aetiological connotations rooted in a particular (i.e., psychodynamic) explanatory model. We will, therefore, use the aetiologically neutral and non-pejorative term-MUS.

Although misdiagnosis of neurological disease as MUS is uncommon, the psychological mechanisms and the manner by which, MUS differs from feigning (i.e., conscious simulation) remains unclear [12]. The "traditional" causal theory for MUS goes back to the writings of Charcot and later Janet, Breuer and Freud in the late 19th century [13]. Common to these theories is the idea that previous trauma, often sexual abuse, can be kept out of conscious awareness by an intrapsychic mechanism and that patients thereby "dissociate" or manifest an aberration of normal conscious integrity. This defensive process then results in symptoms, and or, physical signs. As Freudian models have declined, MUS has generated surprisingly little academic interest and alternative models of psychopathology remain under-developed [11]. Certain of the assumptions of this traditional causal view appear challenged by the findings of contemporary memory research. In a series of studies, Elizabeth Loftus and other researchers have shown that complex memories can be formed through suggestion [14]. Loftus [15] concluded that just because a memory seems detailed, just because a person seems confident in it and just because there is associated emotion, does not mean that it really happened. McNally [16-18] provides an analysis of how memory for trauma can be understood without resorting to explanations of repression.

The recently published "Medically Unexplained Symptoms: Positive Practice Guide, Improving Access to Psychological Therapies" IAPT [19], acknowledge the high prevalence of MUS in primary and secondary care. These guidelines also recognise that it is difficult to Engage this patient group with psychological treatment and that one reason for this is that patients often have a dualistic or physical understanding of their symptoms and do not perceive their symptoms to be related to psychological factors. The Department of Health Guidance: "Talking Therapies: A four-year plan of action”, Department of Health [20], outline how the cost of treating patients with MUS is "so significant that action needs to be taken to address them”, and describes positive outcomes with MUS patients following talking therapy.

Given that MUS is prevalent, that aetiology remains contentious, that psychological treatments for MUS have been slow to develop, that engaging patients in psychological treatment is difficult and, in light of the recent UK IAPT guidance, we conducted a study to explore the beliefs of health professionals in training, (primarily cli- nical psychologists) that may impact upon these important issues.

Our primary research question was to explore whether there exists a gap between what trainee practitioners believe about the aetiology and treatment of MUS and what is cited in the epidemiological and memory literature. Our conjecture was that such a gap does exist. The secondary question addressed views on the mind-brain relationship (i.e., dualistic beliefs) and the association of such ontological beliefs to beliefs about the aetiology and treatment of MUS. It is accepted that many MUS patients hold a dualistic model of mind and this affects engagement with psychological services [19]. We hypothesized that beliefs about the cause of MUS and dualistic attitudes towards mind and brain held by practitioners may have implications for training and clinical practice.

We also included questions about the nature of the human mind and about belief in the existence of a god or gods. These questions were influenced by the work of Demertzi et al. [21], who found that religious beliefs were the best predictor of dualistic thinking. For example, that the soul is separable from the body, or that part of us can survive after death. Such beliefs may influence practitioners' behaviour towards patients [22].

\section{Method}

\subsection{Participants}

Twenty seven Doctorate in Clinical Psychology (D. Clin. Psychol) courses in England and Wales were approached to participate in the study. Twenty three courses agreed to take part. The questionnaire was sent to all trainees via a website link from the course administrator and returned to the researchers anonymously. We did not have data on trainee attrition, but assuming full retention on all courses, we recruited 375 (31\%) of a possible 1207 trainees (figure estimated from published recruitment data).

The study was granted NHS ethical approval with the stipulation of all responses being anonymous at the point of contact and return.

Although clinical psychologists in training constituted our principle sample, we also recruited local samples of neurologists and psychiatrists in training. The weblink questionnaire was sent to 18 neurologists (pre-consultant) -12 (67\%) were returned; and to 42 psychiatrists (preconsultant)—20 (48\%) were returned.

\subsection{Survey}

A 29-item survey was developed for the study. A summary of the questions are included in our Tables of results. Participants were asked about: epidemiology of MUS; when presented with a MUS patient what literature they would turn too; terminology; the association 
between sexual abuse and MUS; psychological models of MUS; how common it is for people not to remember past traumatic events (isolated and prolonged trauma); a brief version of the traditional psychodynamic causal model of MUS was presented; views on whether memories that surface years later in therapy are accurate; whether memories recovered under hypnosis are accurate; whether it is necessary to recover memories of past trauma in order for patients to improve and whether it is possible for people to develop false memories for events that did not happen. Questions were included about treatment of MUS. Participants' views were expressed on 5 point Likert scale (Agree, Somewhat agree, Don't know, Somewhat disagree and Disagree).

Participants were also asked to give their views about the nature of the human mind and about belief in the existence of a god or gods. These questions were about: whether the mind and brain are separate things, whether the mind is reducible to a physical process, belief in a god, whether some spiritual part of oneself survives death, whether the soul is separate from the body and whether the soul is just another term for the mind.

\subsection{Data Analysis}

Data were analysed using SPSS (version 17). Descriptive statistics for all questions and Spearman correlation coefficients between various participants' beliefs were computed. For the psychologists, chi-square was used to test for the effect of training length on beliefs.

\section{Results}

Tables 1-4 show the data on clinical psychology trainees, neurologists and psychiatrists. Given the small sample size of neurologists and psychiatrists, we did not test for group differences.

From Table 1 it can be seen that all three groups held a view that MUS is a highly prevalent clinical condition, with $40 \%$ of psychologists, $22 \%$ of neurologists and $47 \%$ of psychiatrists reporting that more than $25 \%$ of patients that see a doctor have MUS. The groups differed on their use of terminology. Most psychologists (46\%) didn't know what nomenclature to use. All of the neurologists thought that "functional" is the proper term. The psychiatrists held differing views; $26 \%$ endorsed "dissociation", $37 \%$ "conversion disorder" and 74\% "somatoform disorder", with some participants endorsing more than one term.

Data in Table 2 are about beliefs regarding childhood sexual abuse as a risk factor for MUS, about repression, and about the psychodynamic model of MUS. All three groups held a view that sexual abuse was a medium to high risk factor for developing MUS. Only $12 \%$ of the psychologists, $11 \%$ of the neurologists and $5 \%$ of the psychiatrists believed that sexual abuse was a small or low risk factor. Participants were asked whether memories for childhood trauma, such as sexual abuse, can be "blocked out" of conscious memory for many years. Only $10 \%$ of psychologists and $5 \%$ of psychiatrists either didn't know or doubted this. Of the neurologists, $44 \%$ were doubtful whether this could happen. We asked par-

Table 1. Beliefs about epidemiology and terminology.

\begin{tabular}{|c|c|c|c|c|}
\hline \multirow[b]{2}{*}{ Question } & \multicolumn{4}{|c|}{ Participants } \\
\hline & & $\begin{array}{c}\text { D. Clin. Psychol (all years) } \\
\left(\begin{array}{c}\%) \\
(N=375)\end{array}\right.\end{array}$ & $\begin{array}{c}\text { Neurologists in training } \\
(\%) \\
(N=12)\end{array}$ & $\begin{array}{c}\text { Psychiatrists in training } \\
\left(\begin{array}{c}(\%) \\
(N=19)\end{array}\right.\end{array}$ \\
\hline \multirow{4}{*}{$\begin{array}{c}\text { What } \% \text { of patients } \\
\text { seen by Drs have } \\
\text { MUS }\end{array}$} & $5 \%$ & 6.5 & 0 & 0 \\
\hline & $15 \%$ & 25.6 & 22.2 & 21 \\
\hline & $25 \%$ & 27.8 & 55.5 & 26 \\
\hline & $>25 \%$ & 40.1 & 22.2 & 47 \\
\hline \multirow{6}{*}{ Terminology } & Dissociation & 3.7 & 0 & 26 \\
\hline & Repression & 0.8 & 0 & 0 \\
\hline & Functional & 16.9 & 100 & 5 \\
\hline & Conversion Dis. & 5.3 & 0 & 37 \\
\hline & Somatoform Dis. & 27.0 & 0 & 74 \\
\hline & Other/don't know & 46.3 & 0 & 5 \\
\hline
\end{tabular}


Table 2. Beliefs about childhood sexual abuse and memory for trauma.

\begin{tabular}{|c|c|c|c|c|}
\hline \multirow[b]{2}{*}{ Question } & \multicolumn{4}{|c|}{ Participants } \\
\hline & & $\begin{array}{l}\text { D. Clin. Psychol } \\
\text { (all years) (\%) } \\
\quad(N=375)\end{array}$ & $\begin{array}{l}\text { Neurologists in } \\
\text { training (\%) } \\
\quad(N=12)\end{array}$ & $\begin{array}{l}\text { Psychiatrists in } \\
\text { training (\%) } \\
\quad(N=19)\end{array}$ \\
\hline \multirow{6}{*}{$\begin{array}{l}\text { What degree of risk does childhood } \\
\text { sexual abuse present }\end{array}$} & None & 0.3 & 0 & 0 \\
\hline & Minimal & 2.0 & 0 & 5 \\
\hline & Small & 9.3 & 11.1 & 0 \\
\hline & Medium & 35.4 & 22.2 & 42 \\
\hline & High & 30.3 & 55.5 & 53 \\
\hline & Don’t know & 22.2 & 11.2 & 0 \\
\hline \multirow{4}{*}{$\begin{array}{l}\text { Can memories for childhood trauma } \\
\text { (i.e., sexual abuse) be "blocked out” } \\
\text { from conscious memory for many years }\end{array}$} & Yes, quite common & 39.6 & 22.2 & 47 \\
\hline & Yes, but rare & 49.4 & 33.3 & 47 \\
\hline & Don’t know & 8.1 & 33.3 & 5 \\
\hline & No, don't believe this & 2.2 & 11.1 & 0 \\
\hline \multirow{5}{*}{$\begin{array}{l}\text { Is it possible for people to have no } \\
\text { consciousness awareness of prolonged } \\
\text { periods of abuse / past trauma }\end{array}$} & Agree & 14.9 & 0 & 32 \\
\hline & Somewhat agree & 39.0 & 11.1 & 37 \\
\hline & Don’t know & 20.2 & 44.4 & 5 \\
\hline & Somewhat disagree & 19.4 & 22.2 & 15 \\
\hline & Disagree & 5.9 & 22.2 & 10 \\
\hline \multirow{5}{*}{$\begin{array}{l}\text { Memories of past trauma that are } \\
\text { inaccessible to conscious memory or } \\
\text { "blocked out” can cause an alteration in } \\
\text { a person's consciousness/dissociation } \\
\text { and result in physical symptoms such as } \\
\text { altered motor function or non-epileptic } \\
\text { seizures }\end{array}$} & Agree & 31.7 & 44.4 & 58 \\
\hline & Somewhat agree & 42.4 & 11.1 & 42 \\
\hline & Don’t know & 19.1 & 22.2 & 0 \\
\hline & Somewhat disagree & 3.7 & 0 & 0 \\
\hline & Disagree & 2.2 & 22.2 & 0 \\
\hline
\end{tabular}

ticipants whether it is possible for people to have no conscious awareness of prolonged periods of past abuse/ trauma (i.e., to experience "massive" repression). The responses were similar in that only a minority of psychologists and psychiatrists doubted it. Seventy three percent of psychologists and 94\% of psychiatrists either didn't know or agreed. The neurologists were, again, more sceptical with only $11 \%$ in agreement.

We presented participants with a précis of the traditional psychodynamic causal model of MUS (i.e., whether memories for past trauma that are not accessible to conscious memory can cause an alteration in a persons consciousness/dissociation and result in physical symptoms). Only $6 \%$ of psychologists disagreed and 19\% didn't know. All of the psychiatrists agreed. Data from the neurologists were more variable with $56 \%$ agreeing (somewhat or totally) and 22\% in total disagreement. Table 3 shows the data on beliefs about treatment and recovered memories. When asked if there was a useful
Cognitive Behavioural Therapy (CBT) model of MUS, $55 \%$ of psychologists, $83 \%$ of neurologists and $58 \%$ of psychiatrists agreed. An equal number of around 30\% of all groups didn't know.

Nine percent of psychologists, no neurologists and $10 \%$ of psychiatrists disagreed. When asked whether hypnosis is a helpful way to uncover memories that people can not access, only $37 \%$ of psychologists, $11 \%$ of neurologists and $16 \%$ of psychiatrists disagreed. Twentytwo percent of psychologists, 55\% of neurologists and $63 \%$ of psychiatrists thought that hypnosis was a good idea.

Regarding beliefs about whether memories recovered under hypnosis are accurate, 28\% of psychologists and $26 \%$ of psychiatrists agreed. No neurologist agreed with this view. A further $46 \%$ of psychologists, $55 \%$ of neurologists and $37 \%$ of psychiatrists disagreed.

We also asked participants whether memories of past trauma that surface years later in therapy are generally 
Table 3. Beliefs about treatment of MUS and recovered memories.

\begin{tabular}{|c|c|c|c|c|}
\hline \multirow[t]{2}{*}{ Question } & \multicolumn{4}{|c|}{ Participants } \\
\hline & & $\begin{array}{l}\text { D. Clin. Psychol (all } \\
\text { years) (\%) } \\
(N=375)\end{array}$ & $\begin{array}{c}\text { Neurologists in training } \\
(\mathbf{( \% )} \\
(N=12)\end{array}$ & $\begin{array}{c}\text { Psychiatrists in training } \\
\left(\begin{array}{c}\%) \\
(N=19)\end{array}\right.\end{array}$ \\
\hline \multirow{6}{*}{$\begin{array}{l}\text { Is there a useful CBT } \\
\text { model of MUS }\end{array}$} & Agree & 17.1 & 50 & 32 \\
\hline & Somewhat agree & 38.2 & 33.3 & 26 \\
\hline & Don’t know & 35.4 & 33.3 & 32 \\
\hline & Somewhat disagree & 7.0 & 0 & 10 \\
\hline & Disagree & 2.0 & 0 & 0 \\
\hline & Agree & 2.2 & 33.3 & 26 \\
\hline \multirow{3}{*}{$\begin{array}{l}\text { Hypnosis is a helpful way } \\
\text { to uncover memories that } \\
\text { people can not access }\end{array}$} & Somewhat agree & 19.9 & 22.2 & 37 \\
\hline & Don’t know & 39.3 & 33.3 & 23 \\
\hline & Somewhat disagree & 22.2 & 0 & 16 \\
\hline \multirow{6}{*}{$\begin{array}{l}\text { Memories recovered under } \\
\text { hypnosis are accurate }\end{array}$} & Disagree & 15.2 & 11.1 & 0 \\
\hline & Agree & 0.3 & 0 & 0 \\
\hline & Somewhat agree & 5.9 & 0 & 29 \\
\hline & Don’t know & 46.6 & 44.4 & 42 \\
\hline & Somewhat disagree & 28.7 & 22.2 & 21 \\
\hline & Disagree & 17.7 & 33.3 & 16 \\
\hline \multirow{4}{*}{$\begin{array}{l}\text { Memories of past trauma } \\
\text { that surface yrs later in } \\
\text { therapy are generally } \\
\text { accurate }\end{array}$} & Agree & 2.2 & 0 & 10 \\
\hline & Somewhat agree & 25.8 & 0 & 16 \\
\hline & Don’t know & 41.6 & 75.0 & 31 \\
\hline & Somewhat disagree & 23.3 & 1.66 & 37 \\
\hline \multirow{6}{*}{$\begin{array}{l}\text { It is necessary to recover } \\
\text { memories of past trauma } \\
\text { (i.e., sexual abuse) if a } \\
\text { patient is to improve with } \\
\text { psychological therapy }\end{array}$} & Disagree & 6.2 & 1.66 & 5 \\
\hline & Agree & 1.4 & 0 & 0 \\
\hline & Somewhat agree & 19.9 & 0 & 10 \\
\hline & Don’t know & 10.37 & 44.4 & 42 \\
\hline & Somewhat disagree & 43.3 & 44.4 & 26 \\
\hline & Disagree & 23.9 & 11.1 & 21 \\
\hline \multirow[b]{2}{*}{ Question } & \multicolumn{4}{|c|}{ Participants } \\
\hline & & $\begin{array}{c}\text { D. Clin. Psychol (all } \\
\text { years) (\%) } \\
(N=375)\end{array}$ & $\begin{array}{c}\text { Neurologists in training } \\
\qquad(\%) \\
(N=12)\end{array}$ & $\begin{array}{c}\text { Psychiatrists in training } \\
\left(\begin{array}{c}\mathbf{\%}) \\
(N=19)\end{array}\right.\end{array}$ \\
\hline \multirow{5}{*}{$\begin{array}{l}\text { The idea that people can } \\
\text { forget past trauma and } \\
\text { recover these memories } \\
\text { years later in therapy has } \\
\text { done harm to patients and } \\
\text { families }\end{array}$} & Agree & 7.3 & 22.2 & 10 \\
\hline & Somewhat agree & 28.1 & 11.1 & 21 \\
\hline & Don't know & 38.5 & 66.6 & 53 \\
\hline & Somewhat disagree & 21.3 & 0 & 10 \\
\hline & Disagree & 3.9 & 0 & 10 \\
\hline \multirow{5}{*}{$\begin{array}{l}\text { It is possible to develop } \\
\text { false memories or } \\
\text { abuse/trauma that did not } \\
\text { happen }\end{array}$} & Agree & 37.1 & 22.2 & 31 \\
\hline & Somewhat agree & 47.8 & 66.6 & 63 \\
\hline & Don’t know & 10.1 & 11.1 & 5 \\
\hline & Somewhat disagree & 13 & 0 & 0 \\
\hline & Disagree & 2 & 0 & 0 \\
\hline
\end{tabular}


accurate and $28 \%$ of psychologists, no neurologists and $26 \%$ of psychiatrists agreed. When asked whether it was necessary to "recover" memories of past trauma (i.e., sexual abuse) if a patient is to improve with psychological therapy, $21 \%$ of psychologists, $10 \%$ of psychiatrists, but no neurologists believed this to be so. Sixty-seven percent of psychologists, $55 \%$ of neurologists and $47 \%$ of psychiatrists disagreed.

When asked whether the idea that people can forget past trauma and "recover" these memories years later in therapy has done harm to patients and families; $35 \%$ of psychologists, $33 \%$ of neurologists and $31 \%$ of psychiatrists endorsed this view. Most participants in each group didn't know. Twenty-five percent of psychologists, no neurologists and $20 \%$ of psychiatrists disagreed.

\subsection{Difference between Year 1, 2 and Final Year Clinical Psychology Trainees}

The chi-squared analyses for the clinical psychology trainees did not reveal any group differences between years one, two and final year trainees on any item.

\subsection{Associations between Dualistic Beliefs and Beliefs about the Aetiology and Treatment of MUS}

Table 4 shows the results of a series of questions about religiosity and dualistic attitudes. Twenty-seven percent of psychologists, $55 \%$ of neurologists and $84 \%$ of psychiatrists believed in a god or gods. Thirty-six percent of psychologists, $44 \%$ of neurologists and $63 \%$ of psychiatrists believed that some spiritual part of the self survives death. Thirty-three percent of psychologists believed that each of us has a soul that is separate from the body. Twenty-two percent of neurologists and $47 \%$ of psychiatrists endorsed this belief.

When asked whether the mind and brain are separate things, $24 \%$ of psychologists, $73 \%$ of psychiatrists and $16 \%$ of neurologists agreed.

To the statement, since the brain is fundamentally physical, the mind must be reducible to a physical process, the majority of psychologists (64\%) disagreed. The majority of neurologists agreed (67\%) and the psychiatrists were almost equally divided with $35 \%$ agreeing and $45 \%$ disagreeing.

Among the whole sample, belief in the existence of god was strongly associated with belief in some spiritual part of the self surviving death $(r=0.31, P<0.01)$. Belief in god was also associated with belief that the mind and brain are separate $(r=0.12, P<0.05)$ and that the soul is separate from the body $(r=0.22, P<0.01)$.

Belief in the traditional psychodynamic model of MUS was associated with belief in massive repression $(r=0.2$, $P<0.01$ ), whereas belief in a CBT model of MUS was not associated with belief in massive repression. Belief in a psychodynamic model of mind was also associated with a belief that sexual abuse is a causal factor $(r=0.12$, $P<0.05)$.

\section{Discussion}

We have provided data on the beliefs of clinical psychologists, neurologists and psychiatrists in training about medically unexplained symptoms (MUS). In light of the ongoing controversy about the aetiology of MUS, developments in the science of memory and the increaseing recognition that MUS is a common clinical problem, we were motivated to study a range of beliefs that may impact on clinical practice. Second, we were interested in investigating beliefs about the mind-brain relationship (i.e., dualistic beliefs) and again, we hypothesized that such beliefs could have clinical implications and that there was value in delineating such beliefs.

Our data show that psychologists, neurologists and psychiatrists believe that MUS is a common clinical problem. Only a small minority of these three professsional groups believed that sexual abuse was a small risk-factor.

Only a small proportion of psychologists and psychiatrists doubted that the human mind is capable of "massive" repression for distressing events. When participants were presented with a précis of the traditional, and still controversial, causal model of MUS, which posits that memories for past trauma can be kept from consciousness and cause dissociation/physical symptoms, only six percent of psychologists and no psychiatrists disagreed. Neurologists were more sceptical. Only a minority of all three professional groups disagreed that hypnosis was a helpful way to uncover memories that people cannot access. Around one third of each professional group believed that traumatic memories recovered in therapy were reliable.

According to Dennett [23] beliefs can be considered as the inner causes that provide for describing and predicting behaviour to say that someone believes something is to say that someone is predisposed to behave in certain ways under certain conditions. There is ample evidence that this is true for both patients and doctors. It is well recognised that in explaining illness, biomedical indices tend to leave an explanatory gap and that psychological and socio-cultural variables need to be considered. This is the basis of the biopsychosocial paradigm [24] and the self-regulation or illness representations model [25], which has proved useful and influential. For example, patients beliefs need to be incorporated to provide anything like a satisfactory explanation of, mild traumatic brain injury outcome [26], whiplash, chronic fatigue, epilepsy [27] and Gulf War syndrome.

There are also numerous examples of beliefs affecting 
Table 4. Religiosity and dualistic belief.

\begin{tabular}{|c|c|c|c|c|}
\hline \multirow[b]{2}{*}{ Question } & \multicolumn{4}{|c|}{ Participants } \\
\hline & & $\begin{array}{c}\text { D. Clin. Psychol (all years) } \\
\text { (\%) } \\
(N=375)\end{array}$ & $\begin{array}{c}\text { Neurologists in training } \\
\left(\begin{array}{c}(\%) \\
(N=12)\end{array}\right.\end{array}$ & $\begin{array}{c}\text { Psychiatrists in training } \\
\left(\begin{array}{c}(\%) \\
(N=19)\end{array}\right.\end{array}$ \\
\hline \multirow{3}{*}{$\begin{array}{l}\text { Do you believe in the } \\
\text { existence of a god or gods }\end{array}$} & Yes & 26.7 & 55.5 & 84 \\
\hline & No & 47.2 & 33.3 & 16 \\
\hline & Don’t know & 25.3 & 11.1 & 0 \\
\hline \multirow{5}{*}{$\begin{array}{l}\text { Some spiritual part of self } \\
\text { survives death }\end{array}$} & Agree & 17.7 & 44.4 & 47 \\
\hline & Somewhat agree & 18.5 & 0 & 16 \\
\hline & Don’t know & 29.2 & 33.3 & 26 \\
\hline & Somewhat disagree & 6.2 & 0 & 5 \\
\hline & Disagree & 27.0 & 11.1 & 5 \\
\hline \multirow{5}{*}{$\begin{array}{l}\text { Each of us has a soul that } \\
\text { is separate from the body }\end{array}$} & Agree & 11.5 & 22.2 & 10 \\
\hline & Somewhat agree & 21.6 & 0 & 37 \\
\hline & Don’t know & 27.2 & 55.5 & 10 \\
\hline & Somewhat disagree & 11.8 & 0 & 16 \\
\hline & Disagree & 27.0 & 22.2 & 37 \\
\hline \multirow{5}{*}{$\begin{array}{l}\text { The mind and the brain } \\
\text { are separate things }\end{array}$} & Agree & 6.5 & 8.3 & 42 \\
\hline & Somewhat agree & 18.0 & 8.3 & 21 \\
\hline & Don’t know & 7.9 & 8.3 & 16 \\
\hline & Somewhat disagree & 25.6 & 16.6 & 10 \\
\hline & Disagree & 41.6 & 58.3 & 10 \\
\hline \multirow{5}{*}{$\begin{array}{l}\text { Since the brain is } \\
\text { fundamentally physical, } \\
\text { the mind must be } \\
\text { reducible to a physical } \\
\text { process }\end{array}$} & Agree & 5.6 & 42 & 10 \\
\hline & Somewhat agree & 16.9 & 25 & 25 \\
\hline & Don’t know & 12.4 & 25 & 20 \\
\hline & Somewhat disagree & 28.1 & 0 & 10 \\
\hline & Disagree & 36.0 & 8 & 35 \\
\hline
\end{tabular}

the way doctors interpret symptoms and collect evidence. Van Gijn and Bonke [28] demonstrated that the way neurologist's interpreted films of equivalent plantar responses could be biased by a fictitious history. Salmon and colleagues [29] showed those general practitioners' attitudes about MUS influence whether they attend or decline training to improve their communication skills. Vickers et al. [30], showed that acupuncture trials conducted in East Asia were always positive, whereas similar trials in Australia/New Zealand, North America or Western Europe were only positive half the time. In terms of MUS specifically, doctor's illness perceptions about patients with medically unexplained somatic syndromes or patients with conversion disorders have been shown to correlate with how difficult they find interact- ing with such patients [11,31].

Our data show that many professionals continue to hold certain beliefs about contentious issues of mind that are probably out of step with the evidence-based literature and could influence the clinical communication and practice of these professionals.

We also looked at beliefs about the mind-brain relationship (i.e., dualistic beliefs), associations between various views of mind and associations between views of mind and MUS beliefs. Most of the neurologists and a high proportion of the psychiatrists endorsed a belief in a god or gods. Although there was less religiosity among the psychologists, dualistic thinking was prevalent among all three groups, but more so among psychiatrists. Our findings that a significant proportion of health profes- 
sionals regard the mind and brain as separate and an association between religious beliefs and dualistic attitudes are comparable with those of Demertzi et al. [21].

Our work was driven by a conjecture that certain beliefs about MUS were possibly at odds with the scientific literature, particularly the literature on memory. We also conjectured that dualistic attitudes remain common even though the biopsychosocial paradigm has developed to incorporate mind and brain. Both these conjectures were supported. Overall, we hypothesise that the language used and the beliefs held by professionals may impact on doctor-patient communication and affect engagement with psychological treatment.

In conclusion, non-evidence based thinking about the cause of MUS and dualistic beliefs are widespread in our sample. Regardless of whether one views these beliefs as correct and contributing positively to clinical practice, or not; their continuing influence should be acknowledged.

\section{REFERENCES}

[1] S. Reid, S. Wessely, T. Crayford and M. Hotopf, "Frequent Attenders with Medically Unexplained Symptoms: Service Use and Costs in Secondary Care,” The British Journal of Psychiatry, Vol. 180, 2002, pp. 248-253. doi:10.1192/bjp.180.3.248

[2] A. J. Carson, B. Ringbauer, J. Stone, L. McKenzie, C. Warlow and M. Sharpe, "Do Medically Unexplained Symptoms Matter? A Prospective Cohort Study of 300 New Referrals to Neurology Outpatient Clinics,” Journal of neurology, neurosurgery and psychiatry, Vol. 68, No. 2, 2000, pp. 207-210. doi:10.1136/jnnp.68.2.207

[3] A. M. Parry, B. Murray, Y. Hart and C. Bass, "Audit of Resource Use in Patients with Non-Organic Disorders Admitted to a UK Neurology Unit," Journal of neurology, neurosurgery and psychiatry, Vol. 77, No. 10, 2006 , pp. 1200-1201. doi:10.1136/jnnp.2006.089888

[4] F. Mari, C. Bonaventura and N. Vanacore, et al., "VideoEEG Study of Psychogenic Nonepileptic Seizures: Differential Characteristics in Patients with and without Epilepsy,” Epilepsia, Vol. 47, No. S5, 2006, pp. 64-67. doi:10.1111/j.1528-1167.2006.00880.x

[5] P. Ribai, P. Tugendhaft and B. Legros, "Usefulness of prolonged Video-EEG Monitoring and Provocative Procedures with Saline Injection for the Diagnosis of Nonepileptic Seizures of Psychogenic Origin,” Journal of Neurology, Vol. 253, No. 3, 2006, pp. 328-332. doi:10.1007/s00415-005-0991-9

[6] J. Kuyk, F. Leijten, H. Meinardi, P. H. Spinhoven and R. Van Dyck, "The Diagnosis of Psychogenic Non-Epileptic Seizures,” Seizure, Vol. 6, No. 4, 1996, pp. 243-253. doi:10.1016/S1059-1311(97)80072-6

[7] O. Devinsky, F. Sanchez-Villaseñor, B. Vazquez, M. Kothari, K. Alper and D. Luciano, "Clinical Profile of - Patients with Epileptic and Nonepileptic Seizures," Neurology, Vol. 46, No. 6, 1996, pp. 1530-1533. doi:10.1212/WNL.46.6.1530
[8] O. Devinsky and E. Gordon, "Epileptic Seizures Progressing into Nonepileptic Conversion Seizures,” Neurology, Vol. 51, No. 5, 1998, pp. 1293-1296. doi:10.1212/WNL.51.5.1293

[9] A. J. Carson, R. Brown, A. S. David, R. Duncan and M. J. Edwards, et al., "Functional (Conversion) Neurological Symptoms: Research since the Millennium," Journal of Neurologyogy, Neurosurgery and Psychiatry, Vol. 83, No. 8, 2012, pp. 842-850. doi:10.1136/jnnp-2011-301860

[10] S. Wessely and P. D. White, "There Is Only One Functional Somatic Syndrome," The British Journal of Psychiatry, Vol. 185, 2004, pp. 95-96. doi:10.1192/bjp.185.2.95

[11] R. A. Kanaan, D. Armstrong and S. C. Wessely, "Neurologists' Understanding and Management of Conversion Disorder," Journal of neurology, neurosurgery and psychiatry, Vol. 82, No. 9, 2011, pp. 961-966. doi:10.1136/jnnp.2010.233114

[12] T. R. J. Nicholson, J. Stone and R. A. A. Kanaan, "Conversion Disorder: A Problematic Diagnosis,” Journal of neurology, neurosurgery and psychiatry. Vol. 82, No. 11, 2012, pp. 1267-1273. doi:10.1136/jnnp.2008.171306

[13] H. Ellenberger, "The Discovery of the Unconscious: The History and Evolution of Dynamic Psychiatry,” Basic Books, New York, 1970.

[14] J. Pintar and S. J. Lynn, "Hypnosis: A Brief History," Wiley-Blackwell, Hoboken, 2008.

[15] E. F. Loftus, "Planting Misinformation in the Human Mind: A 30-Year Investigation of the Malleability of Memory,” Learning Memory, Vol. 12, No. 4, 2005, pp. 361366. doi:10.1101/lm.94705

[16] R. J. McNally, “Troubles in Traumatology,” The Canadian Journal of Psychiatry, Vol. 50, No. 13, 2005, pp. 815-816.

[17] R. J. McNally, "Debunking Myths about Trauma and Memory,” The Canadian Journal of Psychiatry, Vol. 50, No. 13, 2005, pp. 817-822.

[18] R. J. McNally, “A New Solution to the Recovered Memory Debate,” Perspectives on Psychological Science, Vol. 4, No. 2, 2009, pp. 126-134. doi:10.1111/j.1745-6924.2009.01112.x

[19] IAPT, "Medically Unexplained Symptoms: Positive PraCtice Guide,” IAPT, London, 2008.

[20] Department of Health, "Talking Therapies: A Four-Year Plan of Action,” Department of Health, London, 2011.

[21] A. Demertzi, C. Liew, D. Ledoux, M.-A. Bruno and M. Sharpe, et al., "Dualism Persists in the Science of Mind," Disorders of consciousness, Vol. 1157, 2009, pp. 1-9.

[22] J. Fahrenbergand M. Cheetham, "The Mind-Body Problem as Seen by Students of Different Disciplines,” Journal of Consciousness Studies, Vol. 7, No. 5, 2000, pp. 47- 59.

[23] D. Dennett, “The Intentional Stance,” MIT Press, Cambridge, 1997.

[24] P. White, "Biopsychosocial Medicine," Oxford University Press, Oxford, 2005.

[25] H. Leventhal, D. Nerenz and D. J. Steele, "Illness Representations and Coping with Health Threats,” In: A. Baum, 
S. E. Taylor and J. E. Singer, Eds., Handbook of psychology and Health, Erlbaum, Hillsdale, 1984, pp. 219- 252.

[26] R. Whittaker, S. Kemp and A. House, "Illness Perceptions and Outcome in Mild Head Injury: A Longitudinal Study," Journal of neurology, neurosurgery and psychiatry, Vol. 78 No. 6, 2007, pp. 644-646. doi:10.1136/jnnp.2006.101105

[27] S. Kemp, S. Morley and E. Anderson, "Coping with Epilepsy: Do Illness Representations Play a Role?” British Journal of Clinical Psychology, Vol. 38, No. 1, 1999, pp. 43-58. doi:10.1348/014466599162656

[28] J. Van Gijn and B. Bonke, "Interpretation of Plantar Reflexes," Journal of Neurology, Neurosurgery and Psychiatry, Vol. 40, No. 8, 1977, pp. 787-789.

doi:10.1136/jnnp.40.8.787
[29] P. Salmon, S. M. Al-Marzooqi, G. Baker and J. Reilly, "Childhood Family Dysfunction and Associated Abuse in Patients with Nonepileptic Seizures: Towards a Causal Model,” Psychosomatic Medicine, Vol. 65, No. 4, 2003, pp. 695-700. doi:10.1097/01.PSY.0000075976.20244.D8

[30] A. Vickers, N. Goyal, R. Harland and R. Rees, "Do Certain Countries Produce Only Positive Results?” Controlled Clinical Trials, Vol. 19, No. 2, 1998, pp. 159-166. doi:10.1016/S0197-2456(97)00150-5

[31] J. L. Jackson and K. Kroenke, "Difficult Patient Encounters in the Ambulatory Clinical: Clinical Predictors and Outcomes,” Archives of Internal Medicine, Vol. 159, No. 10, 1999, pp. 1069-1075. doi:10.1001/archinte.159.10.1069 